\title{
Aceitabilidade de biscoitos e bolos à base de arroz com café extrusados
}

\author{
Acceptability of biscuits and rice and extruded coffee-based cakes
}

\author{
Reginaldo Ferreira da SILVA ${ }^{1 \star}$, José Luis Ramirez ASCHERI², \\ Rosemary Gualberto Fonseca Alvarenga PEREIRA³ ${ }^{3}$ Regina Célia Della MODESTA ${ }^{4}$
}

\section{Resumo}

O objetivo deste trabalho foi avaliar a granulometria de farinha do trigo e de farinhas pré-cozidas por extrusão obtidas da mistura de arroz com pó de café (15 e 20\%), bem como a aceitabilidade de biscoitos e bolos elaborados a partir da adição de 20 e $30 \%$ da farinha pré-cozida na mistura da massa (trigo). Os resultados obtidos mostraram que as farinhas extrusadas apresentaram maior granulometria que a farinha de trigo; à medida que se aumentou o percentual de farinha pré-cozida na mistura com o trigo, também aumentou a granulometria. Não houve diferença significativa entre as amostras tratadas com 15 e $20 \%$ de farinha pré-cozida quanto à preferência sensorial de aroma, textura, sabor e impressão global avaliados em bolos. Entretanto, os biscoitos elaborados com a farinha pré-cozida com $15 \%$ de pó de café na mistura com arroz apresentaram maior preferência para aroma e textura ao serem comparados com aqueles com $20 \%$; a farinha pré-cozida de pó de café com arroz pode ser utilizada como ingrediente na mistura de bolos, biscoitos e outros produtos alimentícios em até $30 \%$.

Palavras-chave: extrusão termoplástica; arroz; café; parâmetros físicos; análise sensorial.

\begin{abstract}
The objective of this study was to evaluate the granulometry of wheat flour and flour precooked by extrusion obtained from the mixture of rice and coffee ( 15 and 20\%), as well as the acceptability of biscuits and cakes prepared with 20 and $30 \%$ of precooked flour in the mixture of the dough (wheat). The results obtained show that the extruded flours presented thicker granulometry than the wheat flour. Granulometry increased with the increase of the content of precooked flour in the mixture with wheat. There were no significant differences among the samples treated with 15 and $20 \%$ of precooked flour as to the sensorial preference of aroma, texture, flavor, and global impression. However, the biscuits made with precooked flour with $15 \%$ of coffee in the mixture with rice presented greater preference of aroma and texture if compared with those with $20 \%$. It can be said that up to $30 \%$ of rice and coffee-based precooked flours can be used as ingredient in the mixture of cakes and biscuits and other food products.

Keywords: thermoplastic extrusion; rice; coffee; physical parameters; sensorial analysis.
\end{abstract}

\section{Introdução}

A característica granulométrica da matéria-prima processada constitui aspecto importante na formulação de massas alimentícias e produtos de panificação, pois uma distribuição adequada de partículas permite maior uniformidade do produto final. A absorção de água é uma característica tecnológica altamente influenciada pela granulometria da matéria-prima, com influência direta sobre as características sensoriais como aparência, sabor, textura e o tempo de cozimento das massas alimentícias (BORGES et al. 2003; LINDEN; LORIENT, 1994).

Segundo Pyler (1988), farinha que apresenta granulometria extremamente fina necessariamente não significa qualidade. Altos percentuais de partículas finas nas misturas podem prejudicar a estrutura interna (miolo) de produtos panificáveis, que poderão apresentar alta umidade e gomosidade.
O tamanho da partícula e a concentração de pasta são fatores que influenciam, significativamente, a viscosidade de pasta, a densidade e a textura de produtos à base de carboidratos (IWUOHA, NWAKANMA, 1998). Portanto, o tamanho de partículas do alimento ou de misturas de vários alimentos, são fatores relevantes na elaboração de produtos panificáveis de qualidade.

Atualmente, pesquisas com farinhas mistas foram direcionadas para a melhoria da qualidade nutricional de produtos alimentícios e para suprir a necessidade dos consumidores por produtos diversificados (TIBURCIO, 2000).

Vários fatores devem ser considerados na utilização de farinhas mistas para produção de alimentos. As características das farinhas sucedâneas devem reduzir ao máximo os efeitos

\footnotetext{
Recebido para publicação em 8/1/2008

Aceito para publicação em 22/7/2008 (003130)

${ }^{1}$ Ciência dos Alimentos, Empresa de Assistência Técnica e Extensão Rural - EMATER, ACRE, CEP 69.912-600, Av. Nações Unidas, 2604, Estação Experimental, CP 462,

Rio Branco - AC, Brasil, E-mail: reginaldo.alimentos@gmail.com

2 Tecnologia de Alimentos, EMBRAPA-RJ, CEP 23020-470, Rio de Janeiro - RJ, Brasil, E-mail: ascheri@ctaa.embrapa.br

${ }^{3}$ Departamento de Ciência do Alimento - Universidade Federal de Lavras - UFLA, MG, CEP 37.200-000 - Lavras Minas Gerais, Brasil. E-mail: rosegfa@ufla.br

4 Ciência dos Alimentos, EMBRAPA-RJ, CEP 23020-470, Rio de Janeiro - RJ, Brasil, E-mail: regimode@hotmail.com

${ }^{*} A$ quem a correspondência deve ser enviada
} 
da substituição para se obter alimentos com cor aceitável, sabor agradável e boa textura (CHAUHAN; BAINS , 1985).

Mudanças no processamento e a crescente exigência do consumidor por alimentos com qualidade sensorial, nutricional e que tragam benefícios à saúde incentivam o estudo de novos ingredientes para a indústria de alimentos.

Já a análise sensorial é reconhecidamente um importante instrumento de determinação da viabilidade ou da aceitabilidade de um produto alimentício. Suas aplicações para a indústria são inúmeras, destacando-se, entre elas, o desenvolvimento e o melhoramento de produtos, o controle de qualidade, a estabilidade no armazenamento, a seleção de novas fontes de suprimento, a elaboração de novos produtos e a redução de custos, entre outros (INSTITUTE OF FOOD TECHNOLOGISTS, 1981). Por meio da análise sensorial é ainda possível medir, analisar e interpretar reações características dos alimentos e outros produtos quando estes são submetidos à percepção dos órgãos do sentido humano.

Também por meio da análise sensorial pode-se predizer ou não a viabilidade da adequação tecnológica utilizada na elaboração de um alimento. Entretanto, em alimentos extrusados, as interações entre as variáveis dependentes e independentes são tão complexas que é impossível diferenciar individualmente as influências dessas variáveis nas mudanças que podem ocorrer nas características do produto final (MODESTA, 2006). Em bebidas solúveis ou instantâneas, parâmetros como absorção, solubilidade e viscosidade são considerados atributos sensoriais importantes para se obter o produto desejado. Por outro lado, parâmetros como aparência, textura (maciez ou crocância), são desejados em produtos sólidos como snacks, pellets, biscoitos, bolos, entre outros.

Tendo em vista a importância do tamanho de partículas que compõem o alimento após a moagem, bem como da análise sensorial para predizer ou não a aceitabilidade de um novo produto alimentício, o objetivo deste trabalho foi avaliar a granulometria das matérias-primas, farinha do trigo e farinhas mistas pré-cozidas de arroz com café por extrusão termoplástica, e verificar a aceitabilidade de biscoitos e bolos elaborados a partir destes ingredientes.

\section{Material e métodos}

\subsection{Matéria-prima}

As matérias-primas utilizadas para a realização do estudo foram: quirera de arroz branco (Oryza sativa, L.) e café torrado e moído (Coffea arábica L.), adquiridos no comércio de Campo Grande (Rio de Janeiro - RJ).

\subsection{Classificação granulométrica}

Após o processo de extrusão das misturas de farinha de arroz com o pó de café, os Snacks obtidos foram secados por um período de 15 horas em estufa ventilada a uma temperatura de $50{ }^{\circ} \mathrm{C}$. Em seguida, moídos em moinho de peneira com abertura de malha de $0,5 \mathrm{~mm}$. Para determinar o tamanho das partículas das farinhas pré-cozidas foi utilizado um agitador de peneiras modelo RO-TAP. Foram peneirados $100 \mathrm{~g}$ de cada amostra durante 10 minutos, num conjunto de sete peneiras arredondadas, com aberturas de malhas variando de $20 ; 40 ; 60 ; 80 ; 100 ; 150 ; 200$ mesh e uma base. Em seguida, os conteúdos retidos em cada peneira foram pesados e expressos em porcentagens de retenção, seguindo o procedimento padrão descrito por GERMANI; BENASSI; CARVALHO (1997).

\subsection{Critério de escolha dos melhores tratamentos das misturas extrusadas}

Para utilização das farinhas pré-cozidas na elaboração de biscoitos e bolos, 18 tratamentos foram estudados, Tabela 1. Entretanto, somente dois foram selecionados por apresentar os maiores índices de absorção e de solubilidade em água; menor tamanho de partícula; e por conter 15 e $20 \%$ de pó de café na mistura extrusada com arroz. Os dois tratamentos selecionados foram extrusados nas seguintes condições: Tratamento (7) $15 \%$ de umidade; $160{ }^{\circ} \mathrm{C}$ de temperatura; e $15 \%$ de pó de café na mistura. Tratamento (13) - $16 \%$ de umidade; $180{ }^{\circ} \mathrm{C}$ de temperatura; e $20 \%$ de pó de café na mistura.

A quantidade da farinha pré-cozida, utilizada na mistura com o trigo para o preparo da massa foi de 20 e $30 \%$, respectivamente, ou seja, 200 e 300 g, conforme Quadro 1.

Tabela 1. Delineamento experimental proposto para o processamento das misturas de farinha de arroz com pó de café por extrusão termoplástica.

\begin{tabular}{crrrrr}
\hline \multicolumn{7}{c}{ Nível } \\
\hline Variável & $-1,682$ & -1 & 0 & +1 & $+1,682$ \\
\hline X1 & 14,63 & 16 & 18 & 20 & 21,36 \\
X2 & 126,36 & 140 & 160 & 180 & 193,64 \\
X3 & 6,59 & 10 & 15 & 20 & 23,41 \\
\hline
\end{tabular}

$\mathrm{X}_{1}=$ Umidade da mistura da farinha de arroz com o pó de café (\%); $\mathrm{X}_{2}=$ Temperatura de extrusão da $3^{\text {a }}$ zona de aquecimento $\left({ }^{\circ} \mathrm{C}\right) ; \mathrm{X}_{3}=$ Percentual da adição de pó de café na mistura com a farinha de arroz (\%).

Quadro 1. Ingredientes utilizados na elaboração de biscoitos e bolos à base de farinha pré-cozida de pó de café e arroz.

\begin{tabular}{|lcc|}
\hline \multicolumn{1}{c}{ Ingredientes } & Biscoito & Bolo \\
Farinha de trigo & $300 \mathrm{~g}$ & $600 \mathrm{~g}$ \\
Mistura pré-cozida* & $200 \mathrm{~g}$ & $300 \mathrm{~g}$ \\
Amido de milho & $100 \mathrm{~g}$ & $100 \mathrm{~g}$ \\
Açúcar & $250 \mathrm{~g}$ & $900 \mathrm{~g}$ \\
Ovos & - & $600 \mathrm{~g}$ \\
Margarina & - & $350 \mathrm{~g}$ \\
Leite de vaca & $150 \mathrm{~mL}$ & $800 \mathrm{~mL}$ \\
Sal & $2,5 \mathrm{~g}$ & $5,0 \mathrm{~g}$ \\
Fermento em pó & $10 \mathrm{~g}$ & $30 \mathrm{~g}$ \\
Gordura & $100 \mathrm{~g}$ & - \\
Lecitina & $5 \mathrm{~mL}$ & - \\
\hline
\end{tabular}

*Mistura pré-cozida de arroz com pó de café. 


\subsection{Preparo dos biscoitos e bolos}

Inicialmente misturaram-se os ovos, o açúcar e a margarina por 2 minutos em batedeira até obter-se mistura homogênea. Adicionaram-se à mistura a farinha e o leite, batendo-se por 2 minutos. Ao final, acrescentou-se o fermento e a massa foi batida por mais 1 minuto. Em seguida, colocou-se a massa em fôrma previamente forrada com papel manteiga, levando-a ao forno.

O tempo de cozimento considerado ideal para o bolo foi de 40 minutos à temperatura de $180^{\circ} \mathrm{C}$. Para o cozimento do biscoito utilizou-se uma temperatura de aproximadamente $170{ }^{\circ} \mathrm{C}$, por um tempo de 10 minutos. Ambos os alimentos foram assados em forno industrial da marca Mini Forno Hypo.

O teste de aceitabilidade foi realizado no Laboratório de Análise Sensorial/Instrumental da Embrapa Agroindústria de Alimentos/RJ em cabines individuais sob iluminação de luz vermelha, sendo as amostras dispostas em pires branco de porcelana e servidas em bandejas de aço inoxidável. As amostras foram codificadas com números aleatórios de 3 dígitos e apresentadas aos consumidores de forma balanceada e aleatorizada. Junto com as amostras, foi servida água mineral à temperatura ambiente para limpeza do palato e a ficha do teste contendo uma escala hedônica de 9 pontos, variando de 1 desgostei extremamente a 9 - gostei extremamente (Quadro 2). O teste de aceitabilidade foi realizado com 50 consumidores, sendo 24 homens e 26 mulheres, com idade entre 19 a 33 anos, os quais avaliaram a preferência em relação ao aroma, textura, sabor e impressão global do produto. Duas amostras de biscoitos e duas de bolos de cada tratamento selecionado foram degustadas pelos consumidores em dias alternados.

\subsection{Análise estatística}

Para a análise de dados de granulometria e dos testes de aceitabilidade foram feitas análises de variância, com posterior comparação das diferenças entre as médias pelo teste de Tukey ao nível de $5 \%$ de probabilidade.

\section{Resultados e discussão}

\subsection{Análise granulométrica}

A Tabela 2 apresenta a análise granulométrica da farinha de trigo da mistura pré-cozida de pó de café com a farinha de arroz e da mistura de ambas as matérias-primas com a farinha de trigo para elaboração de biscoitos e bolos.

Observou-se que $95 \%$ da farinha de trigo passou pela peneira $60 \operatorname{ABNT}(0,250 \mathrm{~mm})$, percentual próximo ao recomendado pela portaria de $n^{\circ} 354$, de 18 de julho de 1996, para farinhas de trigo utilizadas na elaboração de bolos (ANVISA, 2007). Portanto, a farinha de trigo apresentou menor granulometria quando comparada com a farinha pré-cozida de pó de café com arroz. Um aumento da substituição de farinha pré-cozida em detrimento da farinha de trigo significou um aumento da granulometria da mistura, com retenção de partículas em peneiras com abertura de 40, 50 e 60 mesh.
Esses resultados encontram-se de acordo com Borges et al. (2006) e Gutkoski; Pedó (2000), que elaboraram bolos a partir da mistura de diferentes concentrações de aveia com farinha de trigo.

O tamanho de partícula do alimento após a moagem constitui aspecto importante no preparo de massas alimentícias e demais derivados, tendo em vista que uma maior uniformidade da granulometria permite a elaboração de um produto final de melhor qualidade sensorial, principalmente, textura, sabor e aspecto visual, pois o alimento absorve água de forma homogênea resultando no cozimento uniforme da massa.

\subsection{Análise sensorial}

As Tabelas 3 e 4 apresentam os resultados dos testes de aceitabilidade dos bolos e biscoitos elaborados com diferentes percentuais de pó de café na mistura extrusada (15 e 20\%)

Quadro 2. Escala Hedônica utilizada no teste de aceitabilidade de biscoitos e bolos formulados com mistura pré-cozida de pó de café com arroz.

\begin{tabular}{|c|c|c|}
\hline \multicolumn{3}{|l|}{$\begin{array}{l}\text { Por favor, prove a amostra e a } \\
\text { com a escala } \\
\text { Produto: }\end{array}$} \\
\hline Código da amostra: & \multicolumn{2}{|c|}{ Amostra (1) } \\
\hline \multicolumn{3}{|l|}{ 9. Gostei extremamente } \\
\hline \multirow{2}{*}{\multicolumn{3}{|c|}{$\begin{array}{l}\text { 8. Gostei muito } \\
\text { 7. Gostei moderadamente }\end{array}$}} \\
\hline & aroma & \\
\hline \multicolumn{3}{|l|}{ 6. Gostei ligeiramente } \\
\hline 5. Indiferente & impressão global & \\
\hline \multicolumn{3}{|l|}{ 4. Desgostei ligeiramente } \\
\hline \multirow{6}{*}{$\begin{array}{l}\text { 3. Desgostei moderadamente } \\
\text { 2. Desgostei muito } \\
\text { 1. Desgostei extremamente }\end{array}$} & \multicolumn{2}{|c|}{ Amostra (2) } \\
\hline & atributos & nota \\
\hline & sabor & \\
\hline & aroma & \\
\hline & textura & \\
\hline & impressão global & \\
\hline
\end{tabular}

Tabela 2. Distribuição percentual do tamanho de partículas de farinha de trigo, farinha extrusada de quirera de arroz com pó de café e da mistura de ambas as matérias-primas.

\begin{tabular}{lcrrrrrrr}
\hline Mesh & $\begin{array}{c}\text { Abertura } \\
\text { (tyler) }\end{array}$ & \multicolumn{7}{c}{ Tipos de farinhas } \\
\cline { 3 - 9 } & & $\mathrm{FT}$ & $\mathrm{T}_{20 \%}$ & $\mathrm{~T}_{13} 3_{15 \%}$ & $\mathrm{M}_{20 \%}$ & $\mathrm{M}_{30 \%}$ & D.M.S. & C.V. \\
\hline 40 & 0,420 & 0 & 1 & 0,3 & 0,2 & 15 & 2,10 & 1,28 \\
50 & 0,300 & 3 & 9 & 22,8 & 40 & 25 & 2,35 & 1,56 \\
60 & 0,250 & 2 & 20 & 28,6 & 45 & 20 & 2,88 & 2,90 \\
80 & 0,180 & 95 & 40 & 52,6 & 15 & 15 & 4,52 & 3,48 \\
100 & 0,150 & 0 & 20 & 0 & 0 & 15 & 1,56 & 1,33 \\
150 & 0,105 & 0 & 10 & 0 & 0 & 0 & 0,09 & 0,20 \\
200 & 0,075 & 0 & 0 & 0 & 0 & 0 & 0,0 & 0,0 \\
Base & - & 0 & 0 & 0 & 0 & 0 & 0,0 & 0,0 \\
\hline
\end{tabular}

FT = farinha do trigo; T720 e T1315\% = Tratamentos com 20\% e 15\% de pó de café na mistura; M20 e M30\% = Mistura com 20\% e 30\% de farinha pré-cozida com farinha de trigo para elaboração de biscoitos e bolos; D.M.S. = Diferença mínima significativa; C.V. = Coeficiente de variação. 
e na massa de formulação de biscoitos e bolos (20 e 30\%), respectivamente.

Observou-se, na Tabela 3, que os tratamentos T13 e T7 foram iguais, apresentando comportamentos semelhantes para todas as características sensoriais avaliadas. A não diferença na preferência por bolos elaborados com 15 e $20 \%$ de pó de café na mistura pré-cozida e 20 a $30 \%$ na formulação com a farinha de trigo credencia qualquer um dos tratamentos a serem utilizados na elaboração de alimentos derivados à base de café. Ambos os alimentos obtiveram médias variando de 6,5 a 6,9, localizadas entre os termos "gostei ligeiramente e gostei moderadamente".

Existe uma regra geral para a formulação de massas adequadas em função do tipo de bolo que se pretende elaborar. Entre os critérios utilizados, um dos mais importantes é que a mistura tenha quantidade suficiente de proteínas de ovos para que, durante o forneamento, a estrutura proteica formada espalhese sobre os componentes da farinha. O descumprimento deste critério prejudicará a textura do bolo em função da formação de estrutura compacta e baixo volume, pois a massa apresentará fraca estrutura proteica, com consequente redução na retenção de gás na massa, o que também influenciará as características de aroma (MORR; HOFFMANN; BUCHHEIM, 2003).

A Tabela 4 mostra que os biscoitos elaborados com $15 \%$ de pó de café na mistura extrusada e $20 \%$ de farinha pré-cozida na massa com o trigo apresentaram diferenças estatísticas $(\mathrm{p}<0,05)$ entre dois dos quatros atributos sensoriais analisados, ou seja, preferência por aroma e textura.

Os ingredientes adicionados em bolos e biscoitos podem ser classificados em materiais de estrutura ou de endurecimento (farinha, sal, leite, água e ovos) e de amaciamento (açúcar,

Tabela 3. Preferência de bolos elaborados com farinha extrusada de arroz com pó de café (20 e 30\%), na mistura com a farinha de trigo.

\begin{tabular}{lcccc}
\hline Bolos & Aroma & Textura & Sabor & Impressão global \\
\hline T13 & $6,6 \mathrm{a}$ & $6,9 \mathrm{a}$ & $6,5 \mathrm{a}$ & $6,6 \mathrm{a}$ \\
T7 & $6,7 \mathrm{a}$ & $6,7 \mathrm{a}$ & $6,6 \mathrm{a}$ & $6,8 \mathrm{a}$ \\
D.M.S. & 0,12 & 0,13 & 0,10 & 0,12 \\
C.V. & 0,03 & 0,02 & 0,01 & 0,02 \\
\hline
\end{tabular}

$\mathrm{T} 13=$ Tratamento $13-\left(15 \%\right.$ de umidade; $160^{\circ} \mathrm{C} ; 15 \%$ de pó de café na mistura $) . \mathrm{T} 7=$ Tratamento 7 - (16\% de umidade; $180{ }^{\circ} \mathrm{C} ; 20 \%$ de pó de café na mistura). Médias com letras diferentes, para cada característica na coluna, diferem ao nível de $5 \%$ de probabilidade pelo teste de Tukey; D.M.S. = Diferença mínima significativa; C.V. = Coeficiente de variação.

Tabela 4. Preferência de biscoitos elaborados com farinha extrusada de arroz com pó de café (20 e 30\%) na mistura com a farinha de trigo.

\begin{tabular}{lcccc}
\hline Biscoitos & Aroma & Textura & Sabor & Impressão global \\
\hline T13 & $6,3 \mathrm{a}$ & $7,2 \mathrm{a}$ & $6,4 \mathrm{a}$ & $6,3 \mathrm{a}$ \\
T7 & $5,6 \mathrm{~b}$ & $6,4 \mathrm{~b}$ & $5,9 \mathrm{a}$ & $5,8 \mathrm{a}$ \\
D.M.S. & 0,21 & 0,30 & 0,20 & 0,27 \\
C.V. & 0,90 & 0,10 & 0,05 & 0,30
\end{tabular}

T13 = Tratamento 13 - (15\% de umidade; $160^{\circ} \mathrm{C} ; 15 \%$ de pó de café na mistura $)$. T7 = Tratamento 7 - (16\% de umidade; $180{ }^{\circ} \mathrm{C} ; 20 \%$ de pó de café na mistura). Médias com letras diferentes, para cada característica na coluna, diferem ao nível de $5 \%$ de probabilidade pelo teste de Tukey; D.M.S. = Diferença mínima significativa; C.V. = Coeficiente de variação. gordura e fermento), dependendo da sua ação no produto acabado. Na mistura, ainda podem ser adicionados farinha de aveia, de soja e de milho, além de uva, passas, tâmaras e outros como materiais de endurecimento (SULTAN, 1986; VITTI; GARCIA; OLIVEIRA, 1988).

Provavelmente, as condições de extrusão do tratamento T13, menor teor de pó de café (15\%), menor percentual de umidade $(15 \%)$ e uma temperatura de extrusão de $\left(160{ }^{\circ} \mathrm{C}\right)$ causaram menor degradação das moléculas responsáveis pelo aroma do pó de café, aumentando, assim, a permanência de gases voláteis na estrutura da massa dos biscoitos após o forneamento por proporcionarem uma estrutura mais compacta em relação ao bolo e, consequentemente, diminuída volatilização desses gases que propiciaram melhores características de aroma.

Já a preferência por textura pode ter sido influenciada pelo tamanho de partículas mais uniforme, tendo em vista que se apresentaram mais homogêneas, com maior percentual de partículas retidas em peneiras de menores aberturas (40 e 60 mesh). A menor quantidade de pó de café na mistura extrusada, e consequentemente menor teor de fibras, provavelmente influenciou de forma positiva, pois os biscoitos apresentaramse ligeiramente crocantes, sendo esta uma das características sensoriais consideradas de grande importância quando se trabalha na produção deste tipo de alimento. Neste tratamento, a proporção de pó de café e farinha de arroz foi de 15\%:75\%, ou seja, $150 \mathrm{~g}$ de pó de café para $750 \mathrm{~g}$ de farinha de arroz. Menor quantidade da farinha pré-cozida também foi adicionada na mistura para elaboração do biscoito de $200 \mathrm{~g}$ em relação ao bolo que foi de $300 \mathrm{~g}$. As médias obtidas para o termo aroma $(6,3)$ e textura $(7,2)$ localizam-se entre "gostei ligeiramente e gostei moderadamente".

\section{Conclusões}

- A farinha de trigo apresentou maior uniformidade em tamanho de partículas;

- Nas farinhas pré-cozidas, quanto maior o percentual de pó de café na mistura com arroz, maior a desuniformidade granulométrica;

- A farinha pré-cozida de pó de café com arroz pode ser utilizada como ingrediente na mistura de bolos, biscoitos e outros produtos alimentícios em até $30 \%$;

- A utilização do pó de café como farinha pré-cozida (15 a 20\%) com o arroz permite a elaboração de produtos panificáveis com características sensoriais que lembram o aroma e sabor do café;

- Biscoitos elaborados com farinha pré-cozida de arroz com $15 \%$ de pó de café na mistura resultam em textura e aroma de boa aceitabilidade.

\section{Referências bibliográficas}

Agência Nacional de Vigilância Sanitária - ANVISA. Portaria no 354, de 18 de julho de 1996. Norma técnica referente à farinha de trigo. Disponível em: http://www.anvisa.gov.br/ anvisalegis/ portarias/354_96.htm. Acesso em: 20 Novembro 2007. 
BORGES, J. T. S. et al. Propriedades de cozimento e caracterização físico-química de macarrão pré-cozido à base de farinha integral de quinoa (Chenopodium quinoa, Willd) e de farinha de arroz (Oryza sativa), polido por extrusão termoplástica. Boletim do Centro de Pesquisas e Processamento de Alimentos, v. 21, n. 2, p. 303-322, 2003.

BORGES, J. T. S. et al. Utilização de farinha mista de aveia e trigo na elaboração de bolos. Boletim do Centro de Pesquisas e Processamento de Alimentos, v. 24, n. 1, p. 145-162, 2006.

BRASIL. Ministério da Saúde. Portaria n²7, de 13 de janeiro de 1998. Aprova o regulamento técnico referente à informação nutricional complementar. Diário Oficial da União. Poder Executivo, Brasília, DF, 16 de Janeiro de 1998. Disponível em: <609http://e-legis.bvs.br/ leisref/public/showAct.php?id=97>. Acesso em: Dezembro 2007.

CHAUHAN, G. S.; BAINS, G. S. Effect of defatted soy flour on the physico-chemical characteristics of extruded rice products. Journal of Food Science and Technology, v. 22, n. 2, p. 155-158, 1985.

GERMANI, R.; BENASSI, V. T.; CARVALHO, J. L. V. Métodos de avaliação de grão e farinha de trigo. Rio de Janeiro: Embrapa, 1997. 84 p. (Documentos, n. 28).

GUTKOSKI, L. C.; PEDÓ, I. Aveia: composição química, valor nutricional e processamento. São Paulo: Varela, 2000. 96 p.

Institute of Food Technologists - IFT. Sensory evaluation guide for testing food and beverage products. Chicago: Food Technology, 1981. p. 50-59. (v. 11).

IWUOHA, C. I.; NWAKANMA, M. I. Density and viscosity of cold flour pastes of cassava (Manihot esculenta Grantz), sweet potato
(Ipoema batatas L. Lam.) and white yam (Discoreia Rotundata Poir) tuber as affected by concentration and particle size. Carbohydrate Polymers, v. 37, n. 1, p. 97-101. 1998.

LINDEN, N. L.; LORIENT, D. Bioquímica agroindustrial. Zaragoza: Acribia, 1994. $426 \mathrm{p}$.

MODESTA, R. C. D. Avaliação sensorial de produtos extrusados. In: ASCHERI, J. L. R. Curso de processos de extrusão de alimentos: aspectos tecnológicos para o desenvolvimento e produção de alimentos para consumo humano e animal. Rio de Janeiro: Embrapa Agroindústria de Alimentos, 2006. p. 60-73.

MORR, C. V.; HOFFMANN, W.; BUCHHEIM, W. Use of applied air pressure to improve the baking properties of whey protein isolates in angel food cakes. Lebensmittel-Wissenschaft und-Technologie, v. 36, n. 1, p. 83-90, 2003.

PYLER, E. J. Baking: science and technology. 3 ed. Kansas: Sosland Publishing Company, 1988. (v. 2).

SULTAN, W. J. Practical baking. 4 ed. New York: Van Nostrand Reibhold, 1986. 713 p.

TIBURCIO, D. T. S. Enriquecimento protéico de farinha de mandioca com farinha de soja de sabor melhorado: desenvolvimento e avaliação nutricional de um novo produto. Viçosa, 2000. 67 p. Dissertação (Mestrado em Ciência e Tecnologia de Alimentos) Universidade Federal de Viçosa - UFV.

VITTI, P.; GARCIA, E. E. C.; OLIVEIRA, L. M. Tecnologia de biscoitos. Campinas: Instituto de Tecnologia de Alimentos, 1988. 88 p. (Manual técnico n. 1). 